\title{
Carboxylate surfactants as efficient and renewable promoters for methane hydrate formation
}

\author{
Xuejian Liu, ${ }^{\dagger}$ Quan Cao,${ }^{*, \dagger}$ Dongyan Xu, ${ }^{\S}$ Shengjun Luo, ${ }^{\dagger}$ Rongbo Guo ${ }^{*, \dagger, \sharp, \S}$
}

\begin{abstract}
†Shandong Industrial Engineering Laboratory of Biogas Production \& Utilization, Key Laboratory of Biofuels of Chinese Academy of Sciences, Qingdao Institute of Bioenergy and Bioprocess Technology, Chinese Academy of Sciences, Qingdao, Shandong
\end{abstract} Province 266101, PR China.

Dalian National Laboratory for Clean Energy, Dalian 116023, China.

${ }^{\S}$ Faculty of Engineering, Qingdao University of Science and Technology, Qingdao 266042, PR China.

\section{Supporting information}

3 pages

1 figure 


\section{Repeated experiments}
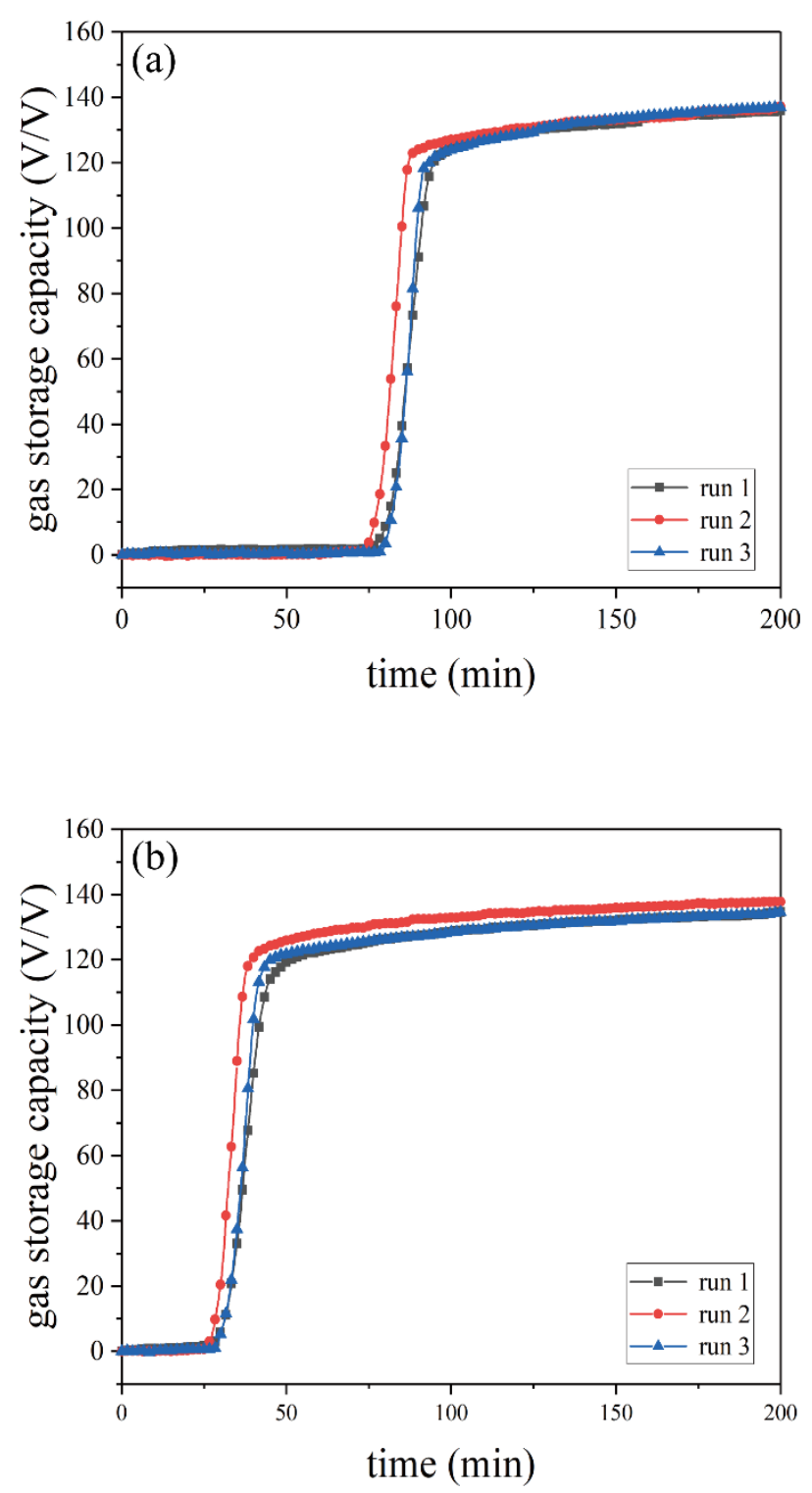

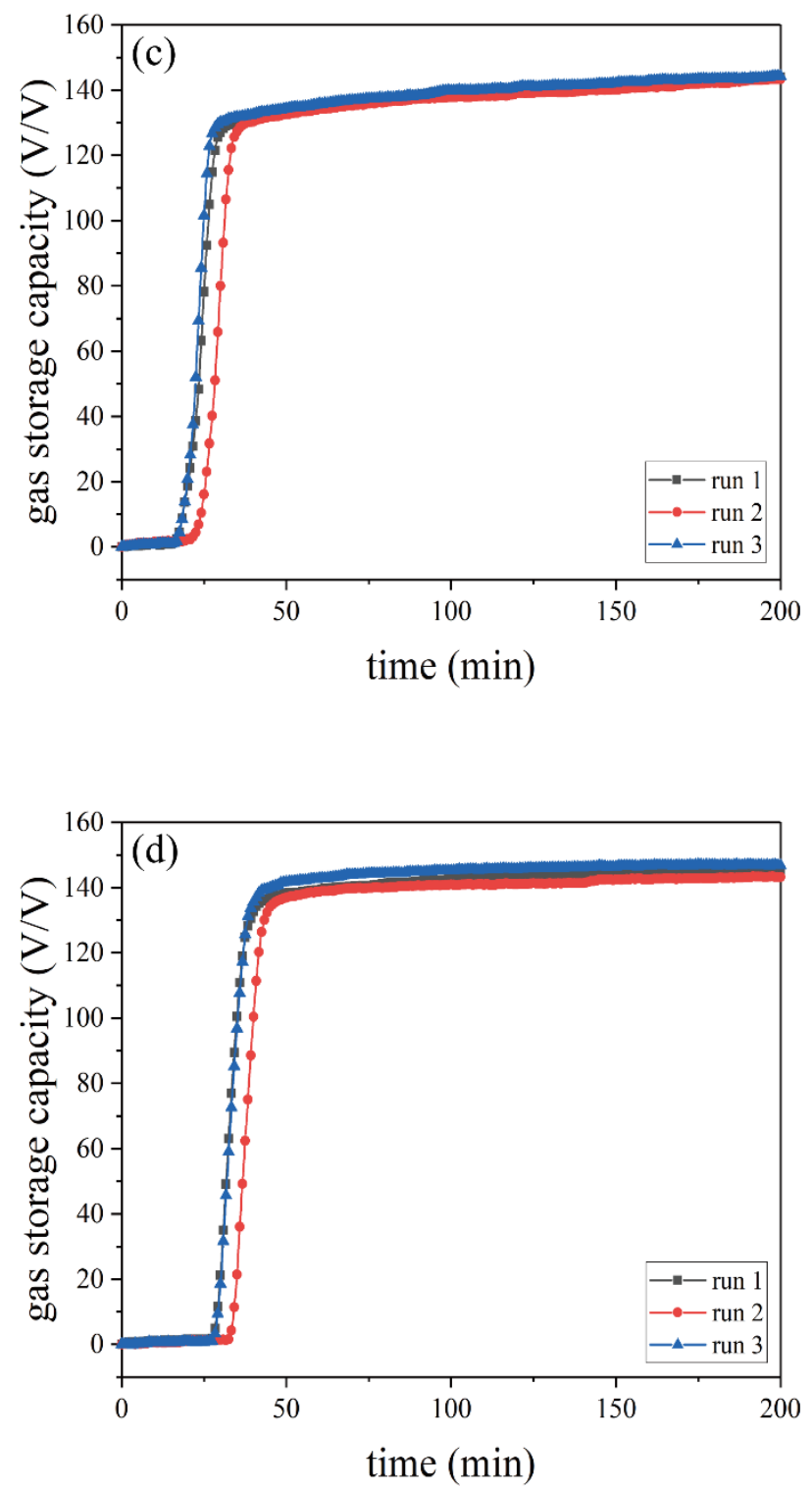

Figure S1. Storage capacity of methane hydrate formed in different solutions. (a): 4 $\mathrm{mmol} / \mathrm{L}$ of decanoic acid and $5 \mathrm{mmol} / \mathrm{L} \mathrm{NaOH}$. (b): $7 \mathrm{mmol} / \mathrm{L}$ of decanoic acid and 8 mmol/L NaOH. (c): $4 \mathrm{mmol} / \mathrm{L}$ of lauric acid and $5 \mathrm{mmol} / \mathrm{L} \mathrm{NaOH}$. (d): $4 \mathrm{mmol} / \mathrm{L}$ of oleic acid and $5 \mathrm{mmol} / \mathrm{L} \mathrm{NaOH}$. Conditions of methane hydrate formation: $2{ }^{\circ} \mathrm{C}, 6 \mathrm{MPa}$ and 300 rpm. 